\title{
STUDY OF SERUM FREE T3 AND FREE T4 IN BLUNT TRAUMA PATIENTS- A CLINICOPATHOLOGICAL CORRELATION.
}

Archana Shukla, Pushpendra Baghel, M. C. Songra

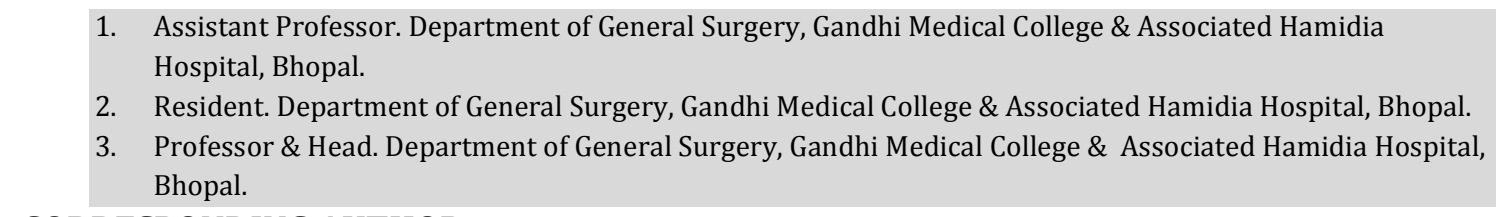

\section{CORRESPONDING AUTHOR:}

Dr. Archana Shukla,

Doctors Quarter,

Hamidia Hospital Campus,

Bhopal-462001.

E-mail: archie2210@gmail.com

Ph: 00919425300644

INTRODUCTION: Survival of patients after hospitalization depends on the nature and severity of injury and also on the life support measures. Evaluating patients who have sustained blunt abdominal trauma remains one of the most challenging and resource-intensive aspects of acute trauma care. Road-traffic accidents are increasing at annual rate of $3 \%$. A vehicular accident is reported every 2 minutes and a death every 8 minutes on Indian roads. ${ }^{1}$ A national survey encompassing various facilities has demonstrated significant deficiencies in current trauma system. ${ }^{1}$ Although, injury is a major public health problem the government medical authority and the society should recognize this challenge. The solution to the problem is implementing a spectrum of injury central activities including surveillance, prevention and treatment for the injured.

Blunt abdominal trauma is a leading cause of morbidity and mortality among all age groups. Many injuries are missed during the initial assessment, examination and treatment period. The frequent causes of increased morbidity and mortality are missed intra-abdominal injuries and concealed hemorrhage, especially in those who survive the initial phase after an injury.

Physical examination findings are notoriously unreliable. Various trauma scores and pathological tests have been developed to determine the prognosis and outcome. Serum levels of thyroid have come out as good predictors for mortality and development of septic complications in recently injured patients. These may prove to be effective parameters in the treatment and prognostication of the patients with injury. The observed thyroid hormone abnormalities do not indicate thyroid disease, but seem to represent a response to the underlying illness, as these invariably disappear with recovery from underlying illness. "Nonthyroidal illness syndrome" (NTIS). ${ }^{2-4}$ NTIS has been depicted in about $70 \%$ of hospitalized patients for different diseases. ${ }^{4}$ In a very recent paper in unselected ICU patients, free $\mathrm{T}_{3}\left(\mathrm{fT}_{3}\right)$ was the most powerful and the only independent predictor of ICU mortality, with a prognostic improving value when added to APACHE II score. ${ }^{5}$

Synthesis and Release of Thyroid Hormones: Synthesis of thyroid hormones requires Iodine, ingested in food and water as iodide, is actively concentrated by the thyroid and converted to organic iodine (organification) within follicular cells by thyroid peroxidase. The follicular cells 
surround a space filled with colloid, which consists of thyroglobulin, a glycoprotein containing tyrosine within its matrix. Tyrosine in contact with the membrane of the follicular cells is iodinated at 1 (monoiodotyrosine) or 2 (diiodotyrosine) sites and then coupled to produce the 2 forms of thyroid hormone (diiodotyrosine + diiodotyrosine $\rightarrow \mathrm{T}_{4}$; diiodotyrosine + monoiodotyrosine $\rightarrow \mathrm{T}_{3}$ ).

$\mathrm{T}_{3}$ and $\mathrm{T}_{4}$ remain incorporated in thyroglobulin within the follicle until the follicular cells take up thyroglobulin as colloid droplets. Once inside the thyroid follicular cells, $\mathrm{T}_{3}$ and $\mathrm{T}_{4}$ are cleaved from thyroglobulin, Free $\mathrm{T}_{3}$ and $\mathrm{T}_{4}$ are then released into the bloodstream, where they are bound to serum proteins for transport, the major one being thyroxine-binding globulin (TBG), which has high affinity but low capacity for $\mathrm{T}_{3}$ and $\mathrm{T}_{4}$. TBG normally carries about $75 \%$ of bound thyroid hormones. The other binding proteins are thyroxine-binding prealbumin (transthyretin), which has high affinity but low capacity for $\mathrm{T}_{4}$, and albumin, which has low affinity but high capacity for $\mathrm{T}_{3}$ and $\mathrm{T}_{4}$. About $0.3 \%$ of total serum $\mathrm{T}_{3}$ and $0.03 \%$ of total serum $\mathrm{T}_{4}$ are free and in equilibrium with bound hormones. Only free $\mathrm{T}_{3}$ and free $\mathrm{T}_{4}$ are available to act on the peripheral tissues. ${ }^{3}$

Thyroid function tests - an overview: Today, the best overall test of thyroid function is to simply determine TSH levels. The high TSH levels are a sensitive indicator of thyroid hypo function and abnormally low levels indicate hyperthyroidism. TSH levels are often raised or low, long before clinical correlates of hypo or hyperthyroidism are noted.

Currently available immunometric assays are sensitive down to 0.1 to $0.2 \mathrm{mIU} / \mathrm{ml}$, or in the case of "third generation" immunochemiluminometric assays, $0.01 \mathrm{mIU} / \mathrm{ml}$. Even with "third generation" immunometric TSH assays, it is important to correlate findings with clinical evaluation of the patient.

In most laboratories, a normal TSH is in the approximate range of 0.3 to $5 \mathrm{mIU} / \mathrm{L}$, should be checked with the local lab, and correlate with the clinical picture. In patients on thyroid hormone replacement, TSH levels under 0.2 are associated with osteoporosis and an increased risk of atrial fibrillation.

Tests other than TSH - total T4, free T3 and T4: Determining a TSH level alone is often a sufficient indication of thyroid function; other tests may sometimes need to be performed. Total T4 levels are often determined, but their utility is small. (Sensitive, reliable immunometric assays exist). The determination of free T4 or T3 levels is of more utility. Free T4 levels may be measured directly by equilibrium dialysis which is expensive and tedious. Indirect determination of free T4 usually involves assay of total T4, and then determining the amount of T4-binding activity in the sample - free hormone levels can then be estimated. Determination of free T3 levels is similar.

Normal free T4 levels vary from laboratory to laboratory, but are generally in the range of about 7 to $20 \mathrm{ng} / \mathrm{L}$ (in our lab $0.70-1.80 \mathrm{ng} / \mathrm{dl}$ ) and normal free T3 values are generally in the range of about 2 to $6 \mathrm{ng} / \mathrm{L}$ (in our lab $1.7-4.2 \mathrm{pg} / \mathrm{ml}$ )

MATERIAL AND METHOD: The present study is a prospective cohort study, conducted at Department Of Surgery, Gandhi Medical College and Associated Hamidia Hospital, Bhopal during October 2011 to October 2012 . The following types of injuries were considered:

- Blunt Injury Chest

- Blunt Injury Abdomen 


\section{Inclusion criteria}

- All patients were in the age group > 20 years and sustained trauma within 24 hrs. of admission.

\section{Exclusion criteria}

- The patient suffering from any concurrent medical illness, with palpable thyroid nodule, with history of any thyroid illness.

$5 \mathrm{ml}$ of venous blood was withdrawn from patients and sent to lab within $1 \mathrm{hr}$. Free thyroid hormone levels were assessed at the time of admission.; $24 \mathrm{hrs;} 48-72 \mathrm{hrs}$ after admission. All hormone levels were assessed using ELISA sandwich method. Outcome was noted in terms of survival and expiry.

PRINCIPLE OF ELISA SANDWICH METHOD: Enzyme-linked immunosorbent assay (ELISA), also known as an enzyme immunoassay (EIA), is a biochemical technique used mainly in immunology to detect the presence of an antibody or an antigen in a sample. The ELISA has been used as a diagnostic tool in medicine and plant pathology, as well as a quality control check in various industries. In ELISA, an antigen is affixed to a surface. The sample with an unknown amount of antigen is immobilized on a solid support (usually a polystyrene micro titer plate) either non-specifically (via adsorption to the surface) or specifically (via capture by another antibody specific to the same antigen, in a "sandwich" ELISA). Then a specific detection antibody linked to enzyme is applied over the surface so that it can bind to the antigen. Between each step the plate is typically washed with a mild detergent solution to remove any proteins or antibodies that are not specifically bound. After the final wash step the plate is developed by adding an enzymatic substrate to produce a visible signal, which indicates the quantity of antigen in the sample. In the final step a substance is added, that the enzyme can convert to some detectable signal, most commonly a colour change in a chemical substrate.

Traditional ELISA typically involves chromogenic reporters and substrates which produce some kind of observable color change to indicate the presence of antigen or analyte. Newer ELISA-like techniques utilize fluorogenic, electrochemiluminescent, and real-time PCR reporters to create quantifiable signals. These new reporters can have various advantages including higher sensitivities and multiplexing. Technically, newer assays of this type are not strictly ELISA as they are not "enzyme-linked" but are instead linked to some non-enzymatic reporter. However, given that the general principles in these assays are largely similar, they are often grouped in the same category as ELISA.

Results: The study has been conducted on patients of acute blunt trauma chest and/or abdomen.

Statistical method used to find correlation of serum free $\mathrm{t} 3$ and free $\mathrm{t} 4 \mathrm{in}$ blunt trauma patients is chi-square test.

Age wise distribution shows $32.5 \%$ of the patients were in the age group of 21-30 years, followed by $25 \%$ in the age group $31-40$ years, $17.5 \%$ in the age group $41-50$ years and $51-60$ years. Only $7.5 \%$ of the enrolled patients were in age group $>60$ years. The minimum age of patient enrolled was 21 years and maximum was 70 years. Gender wise distribution of the patients showed around three-fourth patients (76.25\%) was male while the remaining $(23.75 \%)$ were females. 
Majority of patients enrolled had blunt abdomen injury i.e.53 in no.(66.25\%) and while the remaining 27 (33.75\%) had blunt chest injury. At admission the observations were made in all the 80 patients and mean fT3 and fT 4 levels were observed to be 0.81 and 2.34 respectively.

$24 \mathrm{hr}$ after admission, the observations for fT3 were made in 68 alive patients and the mean value was 0.86 . fT 4 could be assessed in 68 patients only with a mean value of 2.25 .

Between 48-72 hrs after admission the observations for fT3 were made in 66 patients and in 66 patients for fT4 levels. The mean levels for fT3 and fT 4 were observed to be 0.83 and 2.1 respectively.

The proportion of subjects with deranged fT3 values among alive and expired subjects was not significantly different.

The percentage of subjects with deranged fT4 values was significantly higher amongst those who expired $(\mathrm{p}<0.001)$.

12 patients expired within $24 \mathrm{hr}$ of admission; hence at $24 \mathrm{hr}$ interval, the fT 3 and fT4 assessment could be done in 68 patients only.

Between 48-72 hr interval, the assessment for fT3 and fT4 could be done in 66 patients only as two patients had expired within $48 \mathrm{hr}$ of admission. All the patients survived. Proportion wise the expiry was significantly higher amongst females as compared to males.

DISCUSSION: Age wise distribution clearly indicates that maximum proportion of patients enrolled in the study was in 21-30 years age group (32.5\%) and in 31-40 years age group (22.5\%). This age group people enjoy taking risks, perform strenuous jobs and drive fast (Eustace and Wei, 2010; Gulliver and Begg, 2007) 6-7 just because of thrill or because of occupational compulsions (Leigh et al., 1993) ${ }^{8}$ and are the most productive age group.

The proportion of female enrolled were one fourth and males were three fourth in the study. After infancy, and before old age, males engage in more behaviour that exposes them to the risk of injury, experience more injuries, and die more frequently from injuries ( $\mathbf{J}$ Richard Udry, 1998). ${ }^{9}$

The majority of patients enrolled are of blunt trauma abdomen (66.25\%). Proportion wise two third patients were of blunt trauma abdomen and one third of blunt trauma chest.

Proportion wise the expiry was significantly higher amongst females as compared to males.

It was seen that in deranged $\mathrm{fT}_{3}$ and $\mathrm{fT}_{4}$, the proportion of expiry was higher. The percentage of subjects with deranged $\mathrm{fT}_{4}$ values was significantly higher amongst those who expired $(\mathrm{p}<0.001)$.

The proportion of subjects with deranged $\mathrm{fT}_{3}$ values among alive and expired subjects was not significantly different. No effects of thyroid hormone level could be seen amongst patients who survived for more than 48 hours.

The study to investigate the alternations of thyroid hormone in traumatic patients with severe inflammatory response syndrome (SIRS) and multiorgan dysfunction syndrome (MODS) concluded that in severe such patients thyroid hormone levels are significantly low (Gou et al. 2008). ${ }^{10}$ In acute severe trauma patient necessitating hospitalization, the total and free $\mathrm{T} 4$ levels remained normal in the survivors but fell below normal in the fatalities on the samples obtained preceding death (Phillips, Roy H. et al. 1984). ${ }^{11}$ This may be an adaptive response to assumption of metabolic control by the sympathetic nervous system and does not result from caloric deprivation and with the persistence and aggravation of SIRS, there is a progressive 
reduction of thyroid hormone. The study among the thermally injured patients concluded that both fT4 and fT3 values were significantly lower in the unstable patients (Becker et al. 1980). ${ }^{12}$

In our study, proportion wise mortality was higher amongst the females as compared to males. But, women respond better to standardized shock resuscitation compared with similarly severely injured men (McKinley et al. 2002). ${ }^{13}$ Further study with a large study sample is required to draw any conclusion.

In the injured patients observed thyroid hormone levels are abnormal in absence of any thyroid disorder, this represents a response to the underlying illness and disappears after recovery.

Appropriate and timely recognition of abnormalities of thyroid function in various nonthyroidal systemic illnesses has paramount importance because of three main reasons: (a) abnormal results of thyroid function tests can sometimes mimic or at other times mask the biochemical changes observed in patients with intrinsic thyroid disease. (b) The hormonal response in euthyroid sick syndrome represents the part of an adaptive response to illness, so the treatment of these systemic illnesses with thyroxine is not of much help. (c) The severity and nature of changes in thyroid function tests have implications on the prognosis in such cases.

CONCLUSION: On the basis of the results and their analysis the following conclusions are drawn from the present study:

1. Majority of trauma victims were from young most productive age group (21-30 years) therefore some work should be done to raise awareness among youngsters.

2. Males were most affected as compared to females because of more risk taking behaviour, especially fasting driving.

3. Deranged $\mathrm{fT}_{4}$ levels were found to have a significant association with poor outcome.

The findings in the present study suggest the role of hormone levels in prediction of the outcome amongst trauma victims may be important. Free thyroid hormone levels can be considered as a prognostic indicator and these levels could be of clinical use for patient management. Although the mechanism remains an unexplored matter and a multidisciplinary approach to resolve this issue is required.

\section{REFERENCES:}

1. Joshipura MK, Shah HS, Patel PR, Divatia PA Trauma care systems in India - An overview Indian Journal of Critical Care Medicine, Vol. 8, No. 2, April-June, 2004, pp. 93-97

2. "Euthyroid Sick Syndrome: Thyroid Disorders: Merck Manual Professional". Retrieved 2009-03-29

3. Chopra IJ. Clinical review 86:Euthyroid sick syndrome: is it a misnomer? JClin Endocrinaol Metab 1997;82 329-324

4. Wang F, Pan W, Wang H, Pan S, Ge j. Relationship between thyroid function and ICU mortality: Aprospective observation study. Crit Care 2012;16(1)R11

5. Eustace, D.and H.Wei, "The role of driver and gender in moter vehicle fatal crashes," Journal of transportation safety and security, volume2, number1, 28-44,2010. 
6. Pauline Gulliver and Dorothy Begg Personality factors as predictors of persistent risky driving behavior and crash involvement among young adults. Inj Prev. 2007 December; 13(6): 376-381.

7. Leigh JP, Markowitz SB, Fahs M, Shin C, Landrigan PJ. Occupational injury and illness in the United States: estimates of costs, morbidity, and mortality. Arch Intern Med. 1997;157:1557-1568.

8. Udry JR. The nature of gender. Demography 1994;31:561-73.[CrossRef][Medline][Web of Science]

9. Gou DY, Su W, Shao YC, Lu YL. Euthyroid sick syndrome in trauma patients with severe inflammatory response syndrome. Chin J Traumatol 2006 Apr;9(2):115-7.

10. Phillips Roy H. Vallentine William A, Caplan Illis. Circulating thyroid hormone changes in acute trauma: Prognostic implication for clinical outcome. Journal of Trauma Critical Care and Infection. Feb. 1984; 24(2): 154-158.

11. Becker RA, Wilmore DW, Goodwin CW Jr, Zitzka CA, Wartofsky L, Burman KD, Mason AD, Pruitt BA. Free T4, free T3, and reverse T3 in critically ill, thermally injured patients. J Trauma. 1980 Sep;20(9):713-21.

12. Drs McKinley, Kozar, Cocanour, Sailors, Ware et al. Female Hearts Respond Better to trauma, hemorrhage, shock Arch Surg. 2002; 137: 578-584.

13. Sarda AK, Karmarkar MG. Changes in thyroid hormones in patients of surgical trauma. Journal of Postgraduate Medicinei. 1992; 38(3): 117-118.

Table 1 Age wise distribution

\begin{tabular}{|c|c|c|c|}
\hline S. No. & Age group (Years) & No. of cases & Percentage \\
\hline 1 & $21-30$ & 26 & 32.5 \\
\hline 2 & $31-40$ & 20 & 25 \\
\hline 3 & $41-50$ & 14 & 17.5 \\
\hline 4 & $51-60$ & 14 & 17.5 \\
\hline 5 & $>60$ & 6 & 7.5 \\
\hline
\end{tabular}

Table 2 Gender wise distribution

\begin{tabular}{|c|l|c|c|}
\hline S.No. & Gender & No. of cases & Percentage \\
\hline 1 & Female & 19 & 23.75 \\
\hline 2 & Male & 61 & 76.25 \\
\hline
\end{tabular}

Table 3 Type of injury

\begin{tabular}{|c|l|c|c|}
\hline S.No. & Type of Injury & No. of cases & Percentage \\
\hline 1. & Blunt abdomen & 53 & 66.25 \\
\hline 2. & Blunt chest & 27 & 33.75 \\
\hline
\end{tabular}


Table 4 Free harmone level

\begin{tabular}{|c|l|c|c|c|c|c|c|}
\hline S.No. & \multirow{2}{*}{ Time interval } & \multicolumn{3}{|c|}{ fT3 } & \multicolumn{3}{c|}{ fT4 } \\
\cline { 3 - 8 } & & N & Mean & SD & N & Mean & SD \\
\hline 1. & At adm. & 80 & 0.81 & 0.49 & 80 & 2.34 & 0.79 \\
\hline 2. & $24 \mathrm{hr}$ after adm. & 68 & 0.86 & 0.56 & 68 & 2.25 & 0.66 \\
\hline 3. & $48-72$ hr after adm. & 66 & 0.83 & 0.59 & 66 & 2.1 & 0.57 \\
\hline
\end{tabular}

Table 5 Outcome and thyroid hormone levels at day 0

\begin{tabular}{|c|c|c|c|c|c|c|c|}
\hline \multirow[t]{2}{*}{ S.No. } & \multirow[t]{2}{*}{ Levels } & \multicolumn{2}{|c|}{ Alive $(n=68)$} & \multicolumn{2}{|c|}{ Expired $(n=12)$} & \multirow[t]{2}{*}{$\chi^{2}$} & \multirow[t]{2}{*}{$\mathbf{P}$} \\
\hline & & No. & $\%$ & No. & $\%$ & & \\
\hline \multicolumn{8}{|l|}{ I. fT3 } \\
\hline 1. & Deranged & 44 & 64.7 & 8 & 66.7 & \multirow[t]{2}{*}{0.172} & \multirow[t]{2}{*}{0.896} \\
\hline 2. & Normal & 24 & 35.3 & 4 & 33.3 & & \\
\hline \multicolumn{8}{|c|}{ II. fT4 } \\
\hline 1. & Deranged & 8 & 11.8 & 9 & 75 & \multirow[t]{2}{*}{24.4} & \multirow[t]{2}{*}{$<0.001$} \\
\hline 2. & Normal & 60 & 88.2 & 3 & 25 & & \\
\hline
\end{tabular}

Table 6 Outcome and thyroid hormone levels at $24 \mathrm{hr}$

\begin{tabular}{|c|c|c|c|c|c|c|c|}
\hline \multirow[t]{2}{*}{ S.No. } & \multirow[t]{2}{*}{ Levels } & \multicolumn{2}{|c|}{ Alive $(n=66)$} & \multicolumn{2}{|c|}{ Expired $(n=2)$} & \multirow[t]{2}{*}{$\chi^{2}$} & \multirow[t]{2}{*}{$\mathbf{P}$} \\
\hline & & No. & $\%$ & No. & $\%$ & & \\
\hline \multicolumn{8}{|l|}{ I. fT3 } \\
\hline 1. & Deranged & 39 & 59.1 & 1 & 50.0 & \multirow[t]{2}{*}{0.17} & \multirow[t]{2}{*}{0.896} \\
\hline 2. & Normal & 27 & 40.9 & 1 & 50.0 & & \\
\hline \multicolumn{8}{|l|}{ II. fT 4} \\
\hline 1. & Deranged & 8 & 12.1 & 1 & 50.0 & \multirow[t]{2}{*}{2.43} & \multirow[t]{2}{*}{0.119} \\
\hline 2. & Normal & 58 & 87.9 & 1 & 50.0 & & \\
\hline
\end{tabular}

Table 7 Outcome and thyroid hormone levels between

\begin{tabular}{|c|c|c|c|c|c|c|c|}
\hline \multirow[t]{2}{*}{ S.No. } & \multirow[t]{2}{*}{ Levels } & \multicolumn{2}{|c|}{ Alive $(n=66)$} & \multicolumn{2}{|c|}{ Expired $(n=0)$} & \multirow{2}{*}{$\chi^{2}$} & \multirow[t]{2}{*}{$\mathbf{P}$} \\
\hline & & No. & $\%$ & No. & $\%$ & & \\
\hline \multicolumn{8}{|l|}{ I. fT3 } \\
\hline 1. & Deranged & 36 & 54.5 & 0 & 0 & \multirow[t]{2}{*}{-} & \multirow[t]{2}{*}{-} \\
\hline 2. & Normal & 30 & 45.5 & 0 & 0 & & \\
\hline \multicolumn{8}{|c|}{ II. fT4 } \\
\hline 1. & Deranged & 8 & 12.1 & 0 & 0 & \multirow[t]{2}{*}{-} & - \\
\hline 2. & Normal & 58 & 87.9 & 0 & 0 & & \\
\hline
\end{tabular}

Table 8 Gender wise mortality

\begin{tabular}{|c|l|c|c|c|}
\hline S.No. & Gender & Alive & Expired & Percentage \\
\hline 1. & Female & 15 & 4 & 21.1 \\
\hline 2. & Male & 51 & 10 & 16.4 \\
\hline
\end{tabular}




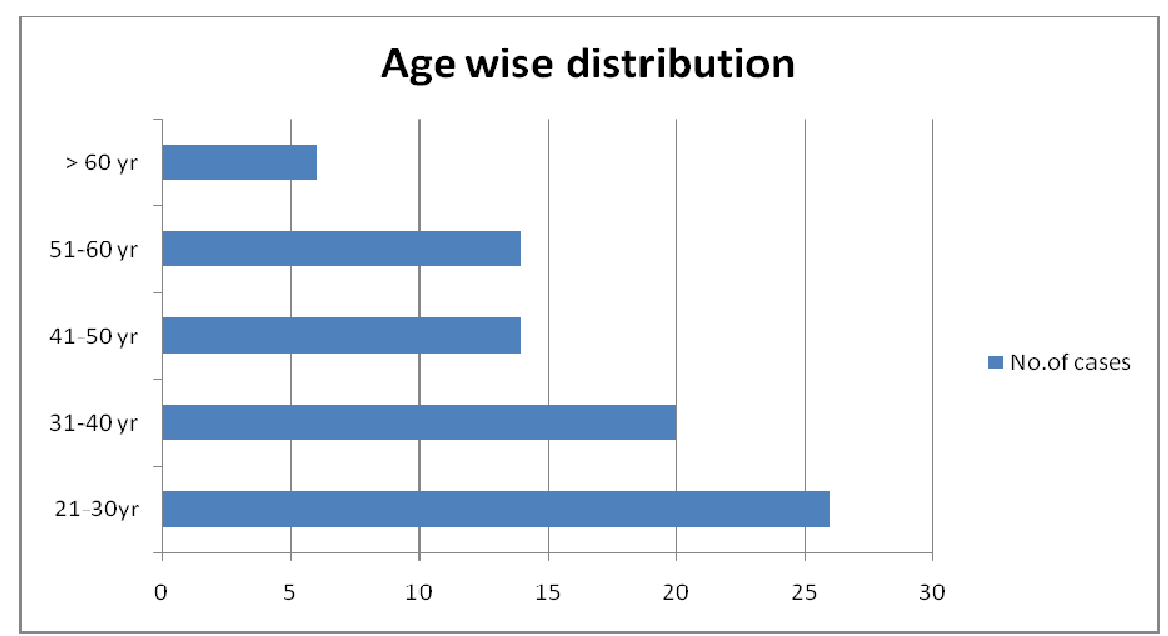

Figure 1 Age wise distribution

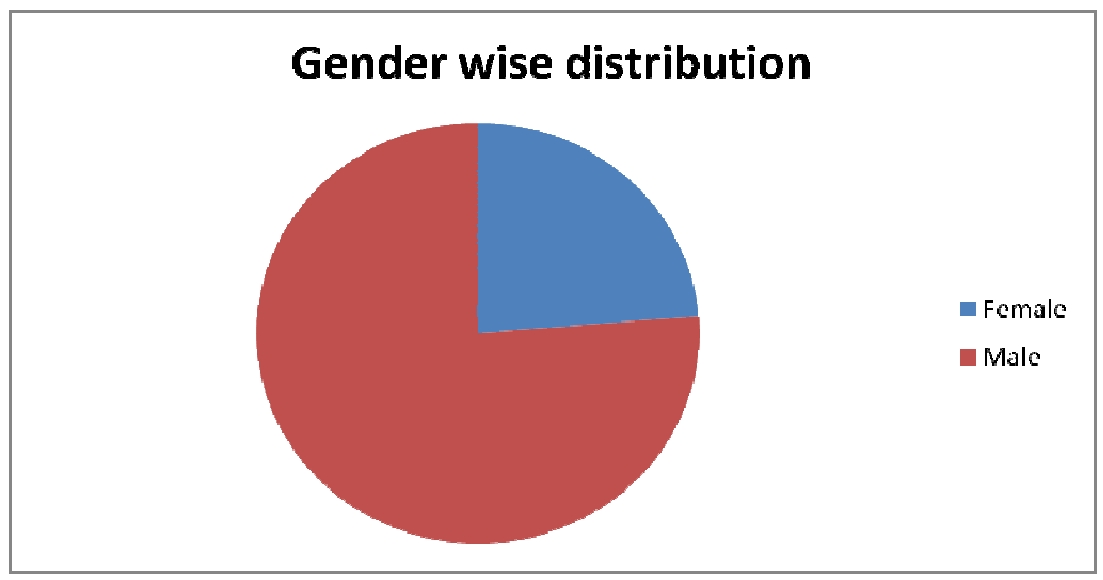

Figure 2 Gender wise distribution

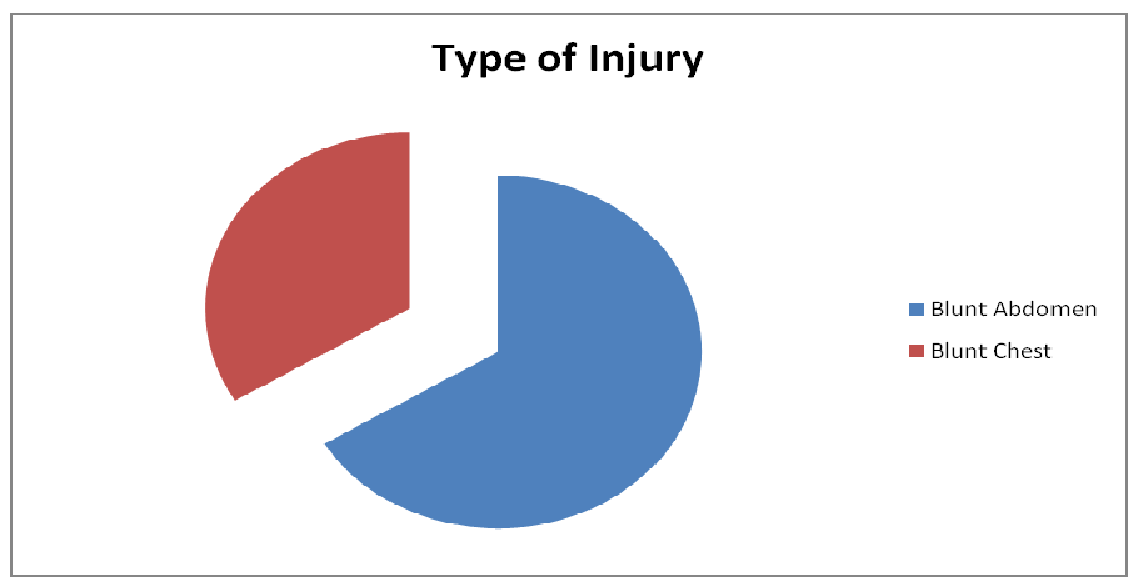

Figure 3 Type of injury 


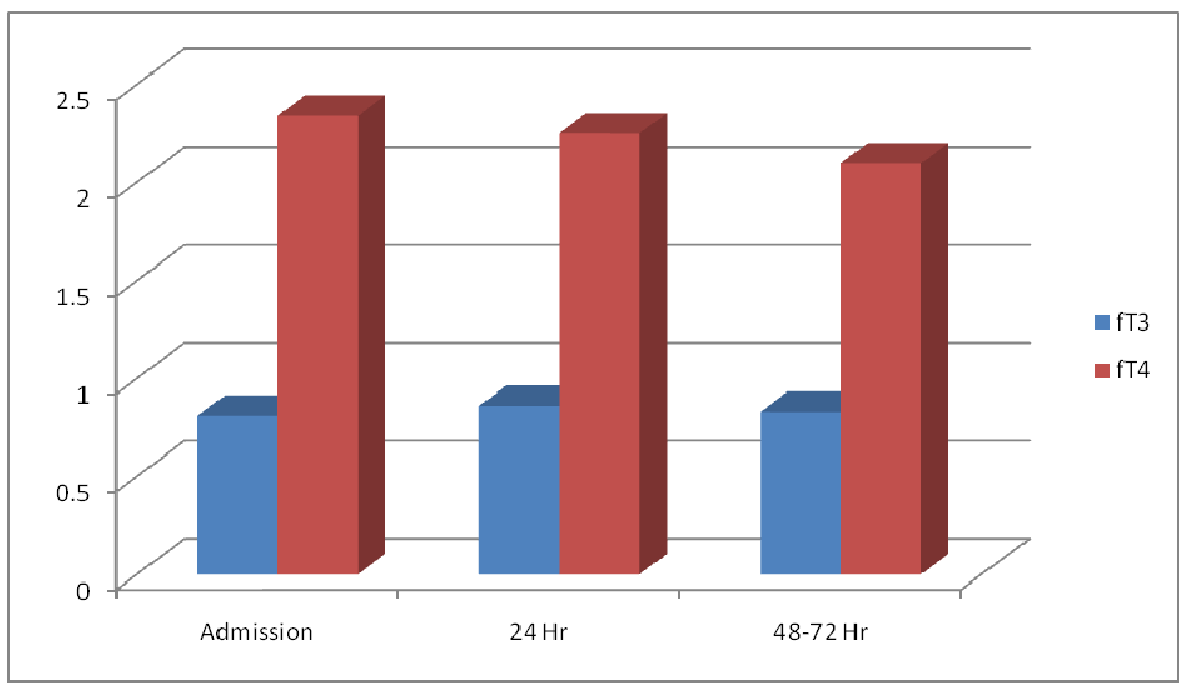

Figure 4 Free harmone level

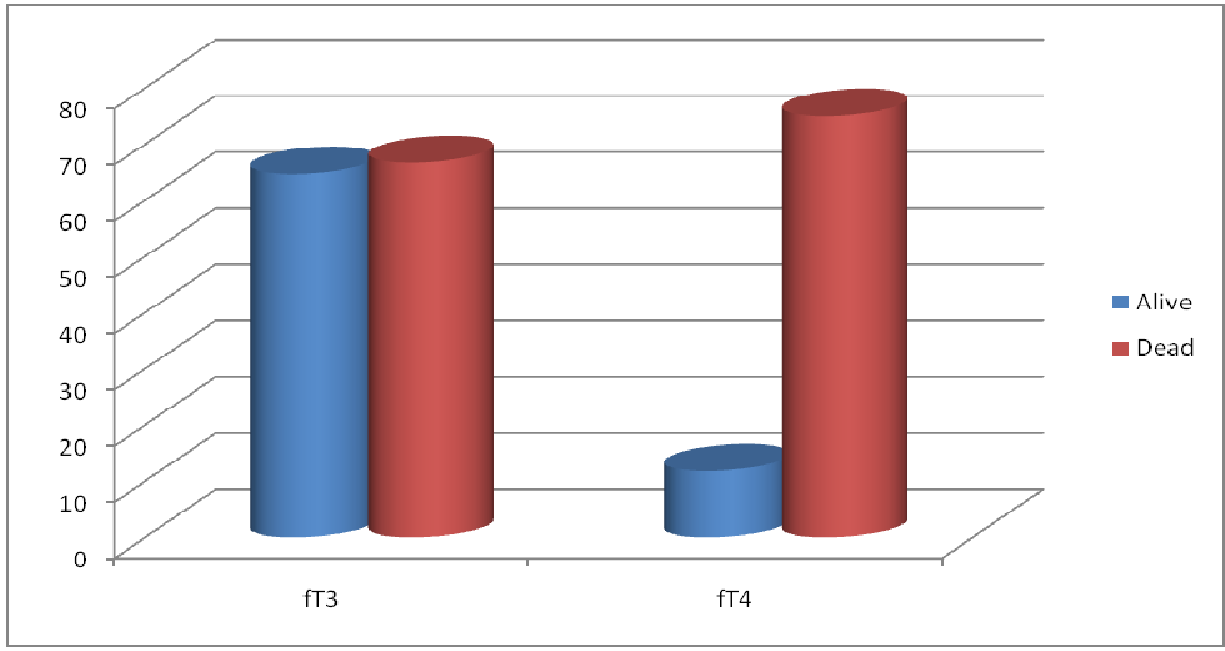

Figure 5 Outcome and thyroid hormone levels at day 0

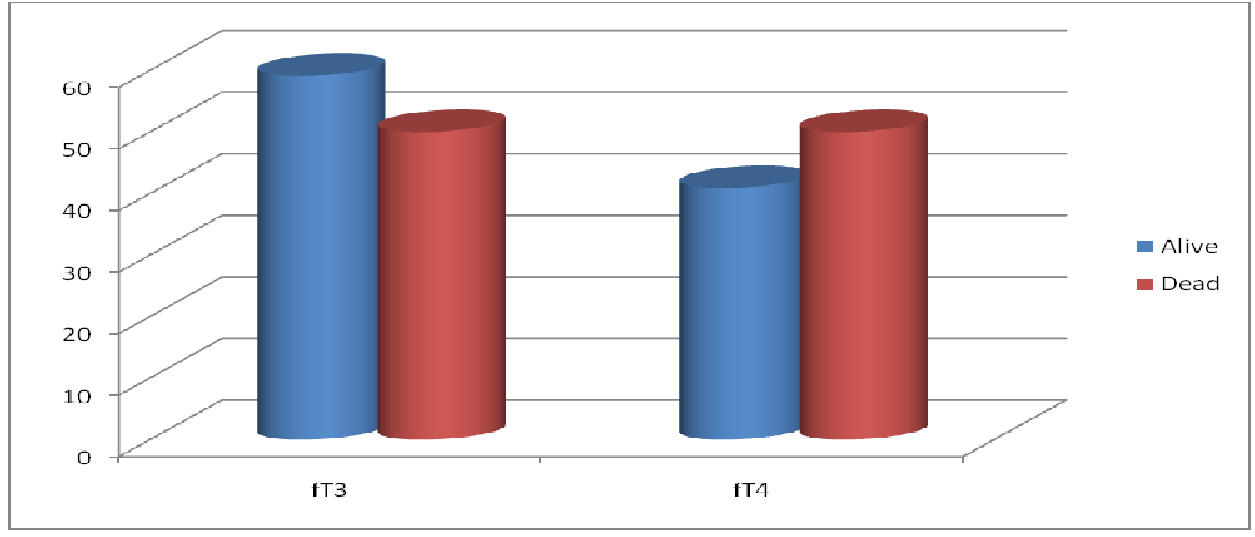

Figure 6 Outcome and thyroid hormone levels at $24 \mathrm{hr}$ 


\section{ORIGINAL ARTICLE}

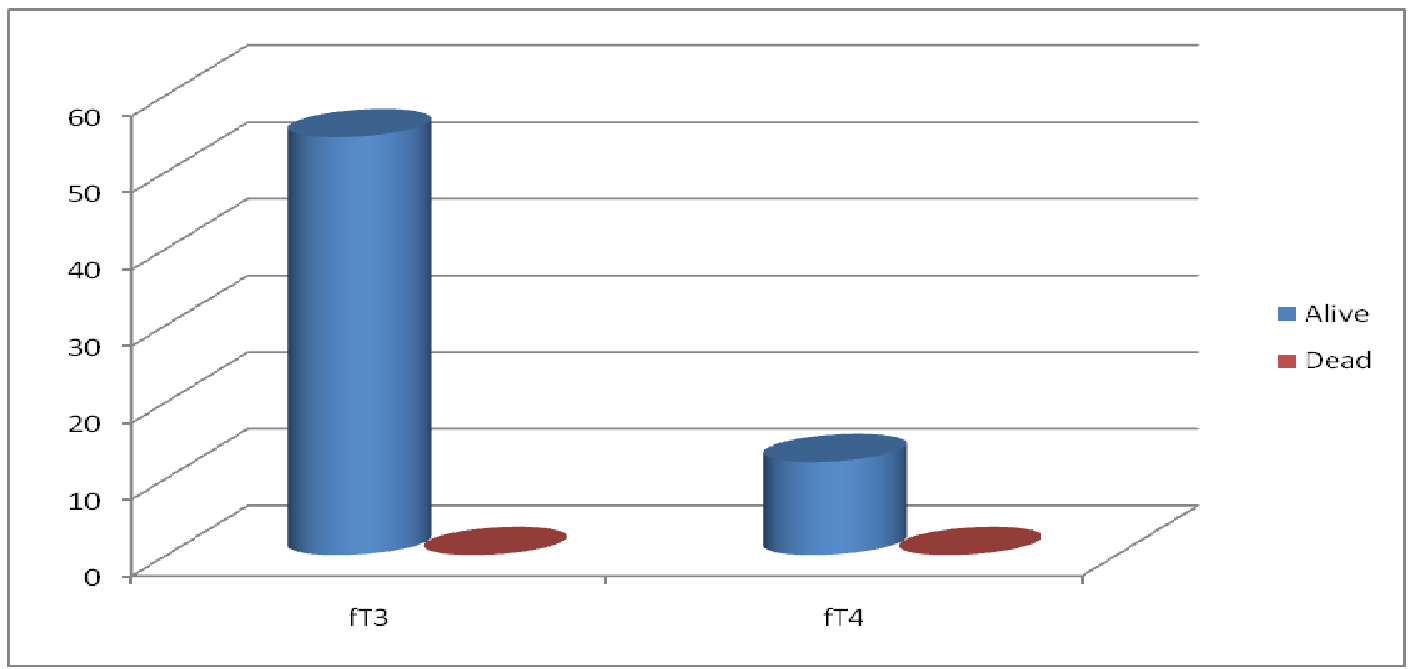

Figure 7 Outcome and thyroid hormone levels between

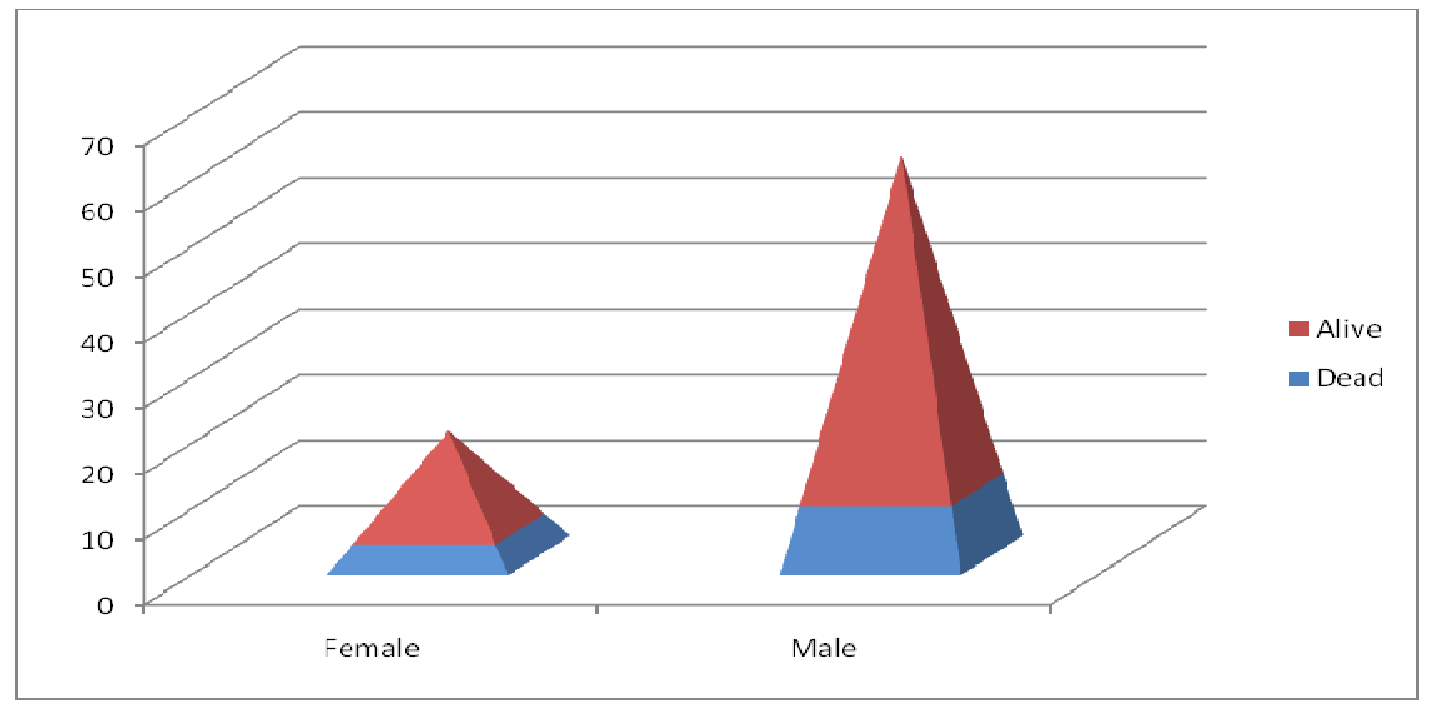

Figure 8 Gender wise mortality 


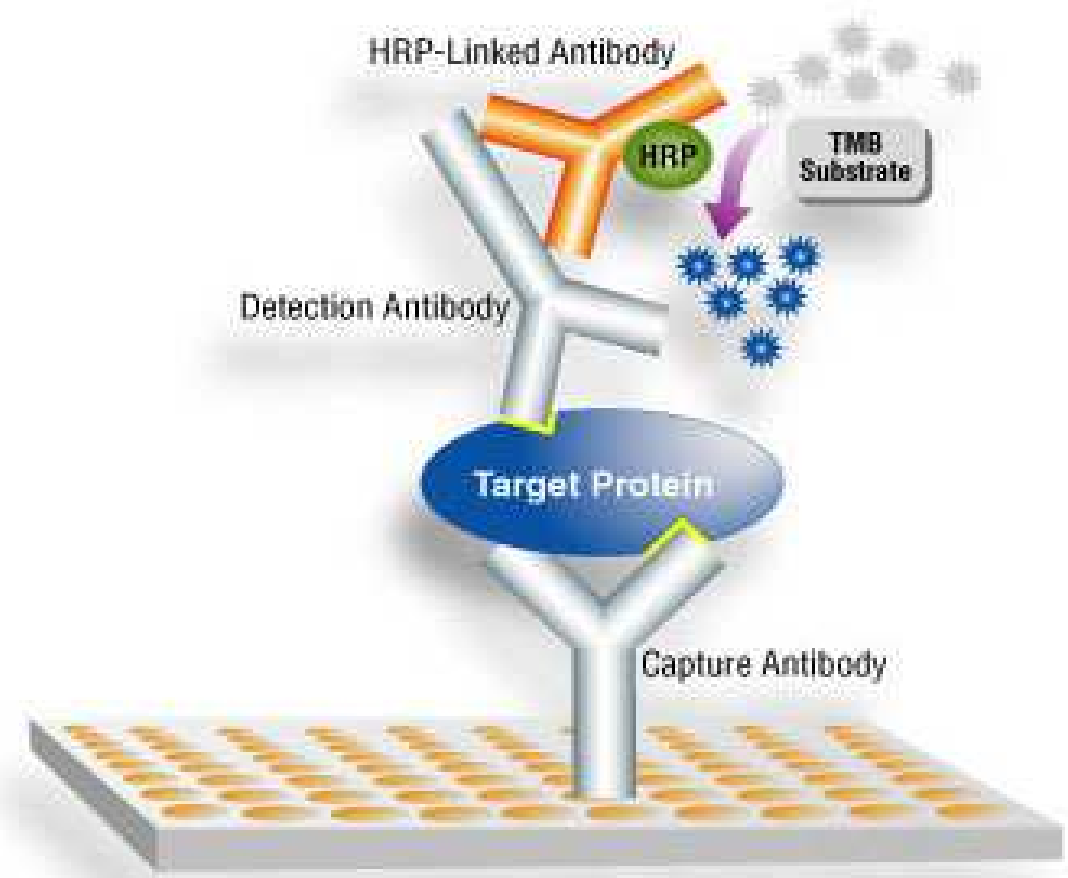

Sandwich Elisa

Figure 9 ELISA sandwich test 